\title{
Socio-demographic study on extent of knowledge, awareness, attitude, and risks of zoonotic diseases among livestock owners in Puducherry region
}

\author{
K. Rajkumar, A. Bhattacharya, S. David, S. Hari Balaji, R. Hariharan, M. Jayakumar and N. Balaji \\ Department of Veterinary Public Health and Epidemiology, Rajiv Gandhi Institute of Veterinary Education and Research, \\ Puducherry - 605 009, India. \\ Corresponding author: K. Rajkumar, e-mail: rajvet10@gmail.com, \\ AB: anjanbhattacharya97@gmail.com, SD: davidjack708@gmail.com, SHB: haribalajichandra30@gmail.com, \\ RH: hariharanram1996@gmail.com, MJ: jayakumar1698@gmail.com, NB: balang248@gmail.com
}

Received: 20-05-2016, Accepted: 19-08-2016, Published online: 26-09-2016

doi: 10.14202/vetworld.2016.1018-1024 How to cite this article: Rajkumar K, Bhattacharya A, David S, Balaji SH, Hariharan R, Jayakumar M, Balaji N (2016) Socio-demographic study on extent of knowledge, awareness, attitude, and risks of zoonotic diseases among livestock owners in Puducherry region, Veterinary World, 9(9): 1018-1024.

\begin{abstract}
Aim: This study was conducted to assess the extent of knowledge, awareness, attitude, and risks of zoonotic diseases among livestock owners in Puducherry region.

Materials and Methods: A total of 250 livestock farmers were selected randomly from eight revenue villages. And each farmer was interviewed with a questionnaire containing both open- and close-ended questions on various aspects of zoonotic diseases, a total of 49 questionnaires were framed to assess the source and transmission of infection to the farmers and to test their knowledge and awareness about zoonotic diseases. The data collected were analyzed by chi-square test using software Graph pad prism, and results were used to assess the relationship between education level and zoonotic disease awareness; risk of zoonotic diseases and its relation with independent variables.

Results: The present survey analysis represents that most of the respondents are belonging to the age group of 41-60 years. About $42.8 \%$ of respondents' household having a graduate. The most of the respondent are small-scale farmers and their monthly income was less than Rs. 10,000. About 61.2\% of farmers were keeping their animal shed clean. About 29.6\% of the respondents were ignorant about cleaning the dog bitten wound. Only $16.4 \%$ of respondents knew that diseases in animals can be transmitted to humans. Only $4.8 \%, 3.6 \%, 6.8 \%$, and $22.4 \%$ of respondents knew about the zoonotic potential of diseases such as brucellosis, tuberculosis (TB), anthrax, and avian flu, respectively. Only $18 \%$ of the respondents were aware about zoonotic diseases from cattle. Regarding the list of zoonotic diseases contracted, 37.7\% reported respiratory infection, $31.1 \%$ digestive disturbances, $15.5 \%$ had dermatological problem, and $15.5 \%$ reported indiscrete disease such as fever, body pain, and headache joint pain. From the respondent got the zoonotic disease ( $\mathrm{n}=45), 51.2 \%$ of the respondent reported chronic infection and $48.8 \%$ of the respondent reported acute form of zoonotic infection. About $30 \%$ of the respondents' farm had an incidence of abortion. Our analyses showed that there was significant in educational level of respondents and treatment of dog bitten animals. Furthermore, there was statistical significance in occurrence of hand and foot lesions in the respondent and occurrence of foot-and-mouth disease outbreak in their animals.
\end{abstract}

Conclusion: From this study, it is concluded that involvement of educated family members in farming practices can create awareness and improve knowledge toward zoonotic disease. Further creation of awareness toward zoonotic diseases is of utmost important.

Keywords: attitude, awareness, livestock farmers, risk, zoonotic disease.

\section{Introduction}

Puducherry is a union territory located in the southern east part of India. It is a coastal region with tropical wet and dry climate. According to $19^{\text {th }}$ livestock census, Puducherry has a livestock population of 95,599 cattle, 141,882 poultry in the rural area and 24,015 cattle, 66,839 poultry in the urban area with the total of $119,614,208,721$ cattle and poultry population [1].

Copyright: Rajkumar, et al. Open Access. This article is distributed under the terms of the Creative Commons Attribution 4.0 International License (http://creativecommons.org/licenses/ by/4.0/), which permits unrestricted use, distribution, and reproduction in any medium, provided you give appropriate credit to the original author(s) and the source, provide a link to the Creative Commons license, and indicate if changes were made. The Creative Commons Public Domain Dedication waiver (http:// creativecommons.org/publicdomain/zero/1.0/) applies to the data made available in this article, unless otherwise stated.
Zoonosis diseases which are naturally transmitted from vertebrate animals to human beings [2]. Approximately, $60 \%$ of all microbial agents of human beings are shared in nature with other animals [3]. Emerging and reemerging zoonotic diseases having a potentially dangerous impact on human health have brought worldwide attention to them [4]. Due to climatic changes, the incidence of emerging and reemerging diseases has increased to a greater extent [5].

The objective of veterinary public health is to improve human health using the knowledge of veterinary science. Salmonellosis, Escherichia coli, campylobacteriosis, and listeriosis which are associated with the current foodborne disease outbreak are of major concern in developing countries. In addition to it, zoonotic diseases such as brucellosis, leptospirosis, rabies, bovine $\mathrm{TB}$, hydatidosis, cysticercosis, 
taeniasis, and toxoplasmosis need attention of veterinary public health service [6].

Animal disease such as anthrax, cysticercosis, brucellosis, bovine TB, rabies, and hydatidosis has an important zoonotic potential [7]. Diseases can also be transmitted to humans through contamination during production, processing, and handling of animal products. Other risk factors contributing to zoonotic outbreaks are working with diseased animals, skinning and slaughtering of infected animals, improper disposal of animal waste, and infective materials of diseases animals. Lack of awareness among livestock owners is the important cause of zoonotic diseases and it is also an important hurdle in controlling zoonotic diseases [8].

Zoonotic diseases have a great impact on livelihood of livestock farmers by affecting their health and reducing the quantity and quality of animal products thereby causing huge economic loss, further economy will be impaired and loss of livestock product market because of decreased consumer confidence [9-11]. Lack of awareness and knowledge about the zoonotic disease reported to be associated with the occurrence of zoonotic disease in humans $[12,13]$. An extensive program was implemented by WHO in controlling rabies in India. Due to this program, economic loss due to rabies in India has drastically come down. A similar type of program if implemented for diseases like leptospirosis and brucellosis, economic losses caused by those diseases in terms of human health and animal health can also be brought down. To implement such program understanding about public knowledge, awareness and animal husbandry practices could be a useful tool in implementing a disease awareness and control program $[2,14,15]$. Hence, this study was undertaken to study the extent of knowledge, awareness, attitude, and risks of zoonotic diseases among livestock owners in Puducherry region.

\section{Materials and Methods}

\section{Ethical approval}

Ethical approval was not required in this survey based study; however, the data were collected after obtaining consent from all the participants.

\section{Sampling area and size}

Puducherry union territory has a total of 81 revenue villages from which a total of 250 livestock farmers were selected randomly from eight revenue villages. And each farmer was interviewed with a questionnaire. Geographical information system map showing 81 revenue villages and area selected for the study was shown in Figure-1.

\section{Data collection}

The questionnaire containing both open- and close-ended questions on various aspects of zoonotic diseases, i.e., awareness, knowledge, risks, animal

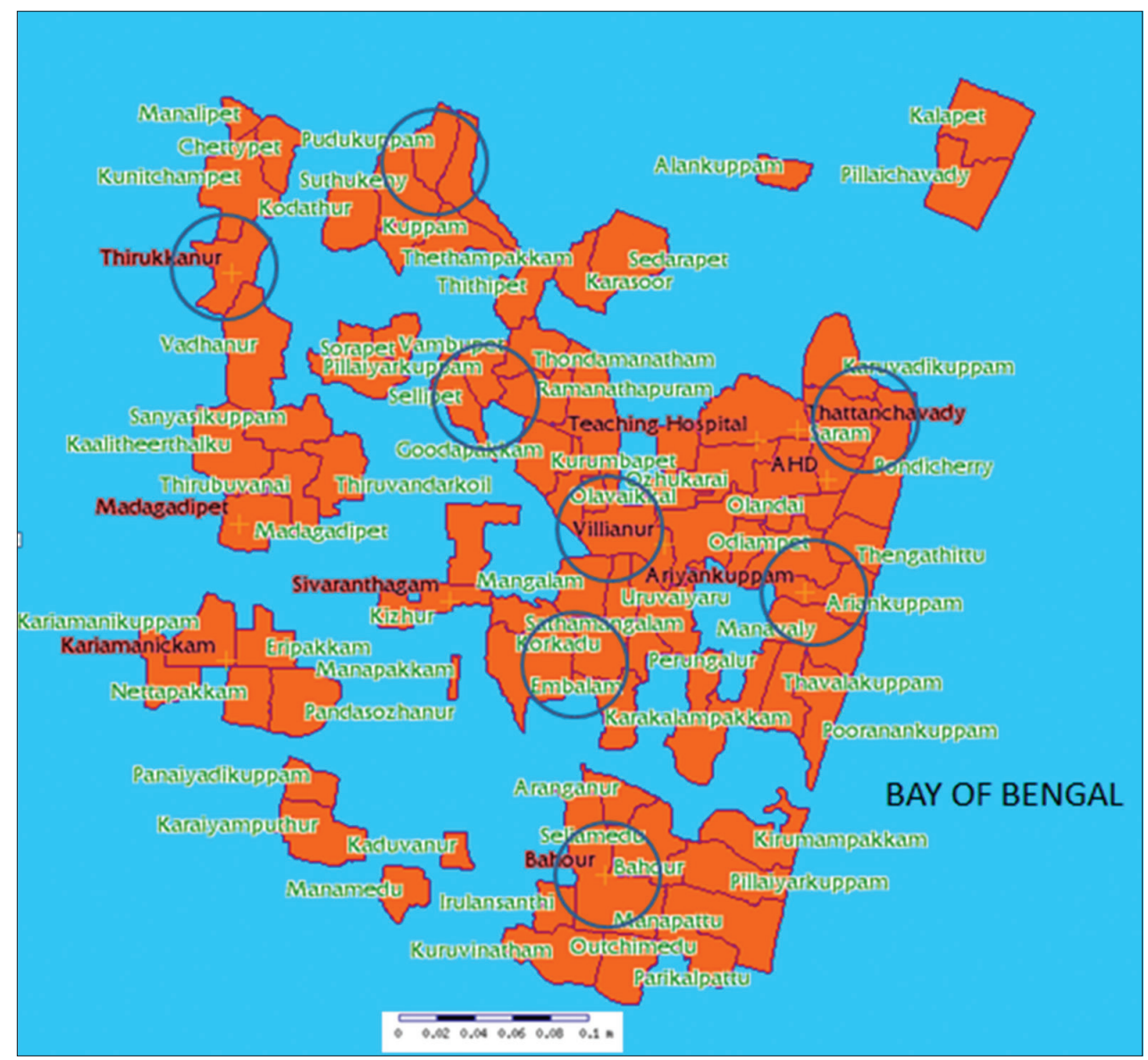

Figure-1: Geographical information system map of Puducherry showing 81 revenue villages and sampling area represented by a circle. 
waste disposal, and personal hygiene was used to interview the respondents. A total of 49 questionnaires were framed to assess the source and transmission of infection to the farmers and to test their knowledge and awareness about zoonotic diseases. The information about independent variables, viz., education, income, age, animal waste disposal, and herd size was collected with the help of structured schedule and scales.

\section{Statistical analysis}

The data collected were analyzed by chi-square test using software Graph pad prism, and results were used to assess the relationship between education level and zoonotic disease awareness; risk of zoonotic diseases and its relation with independent variables.

\section{Results}

\section{Education and socioeconomic status of the livestock} farmers

Based on the study conducted in Puducherry, it has been found that the majority of farmers involved in livestock rearing are primarily educated (Figure-2). Moreover, the majority of them are able to read and write in their mother tongue.

The present survey analysis represents that most of the respondents are belonging to the age group of 41-60 years (Table-1) and many of them are women

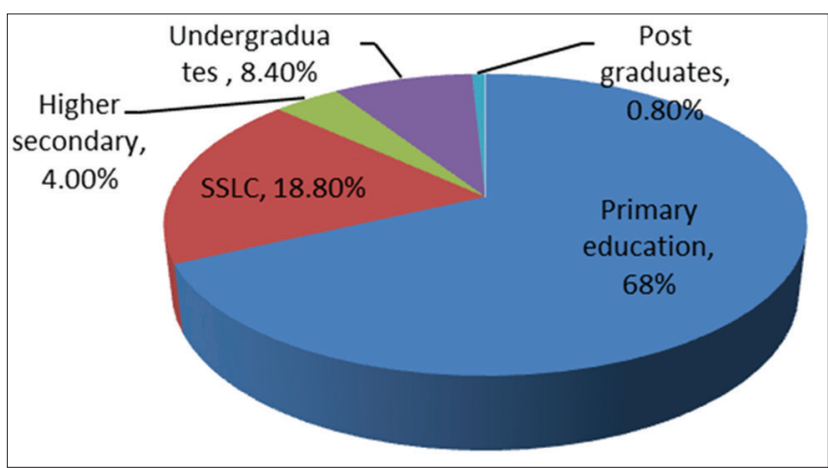

Figure-2: Educational qualification of the respondents (farmers).

Table-1: Respondents age.

\begin{tabular}{lcc}
\hline Age (years) & Frequency (\%) & $\begin{array}{c}\mathbf{9 5 \%} \text { confidence } \\
\text { interval }\end{array}$ \\
\hline$<25$ & $19(7.6)$ & $4.92-11.56$ \\
$26-40$ & $62(24.8)$ & $19.86-30.51$ \\
$41-60$ & $115(46)$ & $39.93-52.19$ \\
$>60$ & $54(21.6)$ & $16.95-27.11$ \\
Total & $250(100)$ & - \\
\hline
\end{tabular}

since they do not like to go out and work. And livestock rearing is considered as one of the most important sources of livelihood by the farmers.

About $42.8 \%$ of respondents' household having a graduate which in turn indicates that easy accessibility to higher level of education is present in rural people of Puducherry (Table-2).

The present investigation reveals that most of the respondents are small-scale farmers and their monthly income was less than Rs. 10,000 which makes living more arduous (Table-3).

Awareness, knowledge and risk factors associated with animal management toward zoonotic diseases

About $61.2 \%$ of farmers were keeping their animal shed clean, implicating their traditional way of maintaining the animals. This also indicates less chance of getting many diseases from the animals by the livestock farmers (Figure-3).

Various awareness programs implemented by Puducherry government toward control of rabies was reflected on by the majority of the respondents $(48 \%)$, who suggested that for dog bitten wound, immediate action was to be taken by cleaning the wound with soap. But still $29.6 \%$ of the respondents were ignorant about cleaning the dog bitten wound. Around $1.2 \%$ of the respondent still suggests application of chili powder on the dog bitten wound (Table-4).

As for the awareness toward zoonoses is concerned, only $16.4 \%$ of respondents knew that diseases in animals can be transmitted to humans. Of those respondents, $51.29 \%$ of them knew some specific zoonotic diseases. Majority of them knew that diarrheic diseases in livestock can be contracted by them. Three respondents mentioned foot-and-mouth disease (FMD) as a potential zoonotic disease.

About $4.8 \%, 3.6 \%, 6.8 \%$, and $22.4 \%$ of respondents knew about the zoonotic potential of diseases like brucellosis, TB, anthrax, and avian flu, respectively. Among 28 respondents who own dogs, only $14.3 \%$ were doing proper deworming. Calf hood vaccination against brucellosis was known only to $0.8 \%$ of the respondents (Table-5).

In this study, about $43.2 \%$ of the responded reported FMD outbreak in their cattle and $24.07 \%$ reported hand and foot lesion after attending the FMD infected animals (Table-6).

Regarding the list of zoonotic diseases contracted by the livestock owners in Puducherry region, $18 \%$ of the respondents were aware about zoonotic

Table-2: Highest education in the family members.

\begin{tabular}{llcc}
\hline Category & Education & Frequency (\%) & 95\% Confidence interval \\
\hline 1. & Primary education & $50(20)$ & $15.51-25.4$ \\
2. & SSLC & $47(18.8)$ & $14.44-24.10$ \\
3. & Higher secondary & $46(18.40)$ & $14.09-23.67$ \\
4. & Undergraduates & $86(34.4)$ & $28.79-40.48$ \\
5. & Post graduates & $21(8.4)$ & $5.56-12.50$ \\
& Total & $250(100)$ & - \\
\hline
\end{tabular}


diseases from cattle. Among the respondents who have contracted zoonotic diseases, $37.7 \%$ reported respiratory infection, $31.1 \%$ digestive disturbances, $15.5 \%$ had dermatological problem and $15.5 \%$ reported indiscrete disease such as fever, body pain, headache, and joint pain. From the respondents who have got the zoonotic disease $(n=45), 51.2 \%$ of the respondent reported chronic infection and $48.8 \%$ of the respondent reported acute form of zoonotic infection (Table-7).

In this study, the facts were revealed that in about $30 \%$ of the respondents' farm had an incidence of abortion. Among them, $25.3 \%, 32 \%$ and $45.3 \%$ of them noted abortions at $1^{\text {st }}, 2^{\text {nd }}$ and $3^{\text {rd }}$ trimester of gestation, respectively (Figure-4).

Table-3: Average monthly income of the respondents' family.

\begin{tabular}{lcc}
\hline Income/month & Frequency (\%) & $\begin{array}{c}\mathbf{9 5 \%} \text { confidence } \\
\text { interval }\end{array}$ \\
\hline$\leq 10,000$ & $198(79.2)$ & $73.75-83.77$ \\
$10,000-20,000$ & $41(16.4)$ & $12.33-21.49$ \\
$\geq 20,000$ & $11(4.4)$ & $2.47-7.71$ \\
Total & $250(100)$ & - \\
\hline
\end{tabular}

Table-4: First aid proposed by respondents' for a dog bite wound.

\begin{tabular}{lcc}
\hline Method of first aid & $\begin{array}{c}\text { Frequency } \\
\mathbf{( \% )}\end{array}$ & $\begin{array}{c}\mathbf{9 5 \%} \text { confidence } \\
\text { interval }\end{array}$ \\
\hline Wash with water & $48(19.2)$ & $14.80-24.53$ \\
Wash with soap & $122(48)$ & $42.67-54.97$ \\
Put chilly powder & $3(1.2)$ & $0.41-3.47$ \\
No washing & $74(29.6)$ & $24.28-35.53$ \\
Total & $250(100)$ & - \\
\hline
\end{tabular}

Table-5: Awareness about zoonotic disease by respondents' of Puducherry region.

\begin{tabular}{lc}
\hline Facts known/activity done & $\begin{array}{c}\text { Frequency } \\
(\%)\end{array}$ \\
\hline Disease can transmit from animals $\rightarrow$ Humans & $41(16.4)$ \\
Specific zoonoses known & $21(8.4)$ \\
Brucellosis known & $12(4.8)$ \\
Wash with soap on dog bitten wound & $122(48)$ \\
Cattle can get TB & $24(9.6)$ \\
TB from livestock $\rightarrow$ Humans & $9(3.6)$ \\
TB from humans $\rightarrow$ Livestock & $15(6)$ \\
Testing livestock for TB & $11(4.4)$ \\
Anthrax from livestock $\rightarrow$ Humans & $17(6.8)$ \\
Vaccination for brucellosis & $2(0.8)$ \\
Deworming of pet dog among dog owners & $4(14.3)$ \\
Avian flu from poultry $\rightarrow$ Humans & $56(22.4)$ \\
\hline
\end{tabular}

$\mathrm{TB}=$ Tuberculosis

Table-6: Zoonotic potential of FMD among livestock owners in Puducherry region.

\begin{tabular}{lc}
\hline Parameter & Frequency (\%) \\
\hline FMD occurrence & $108(43.2)$ \\
Hand lesions among owners & $26(24.07)$ \\
handled FMD animal & \\
\hline
\end{tabular}

FMD =Foot-and-mouth disease
Relationships between different variables analyzed by Chi-square test

Different independent variables were analyzed by chi-square test and Fisher's exact test and data and statistical significance were represented in Table-8. The data revealed that there was no significance in the income of the respondent and their method of disposal of carcasses; frequency of livestock shed cleaning and incidence of disease symptoms among respondents; habit of sleeping inside cattle shed and incidence of disease symptoms among respondents; education level of dog owners and deworming, vaccination of their pets.

Further our analyses showed that there was a significant relationship in the educational level of respondents and treatment of dog bitten animals. Furthermore, there was statistical significance in occurrence of hand and foot lesions in the respondent and occurrence of FMD outbreak in their animals.

\section{Discussion}

The interface among people, animal and the surrounding environment is very close in many developing and developed countries, where animals act as a companion and provide draught power, transportation, clothing, fuel and source of protein in the form of milk, meat and eggs. In the absence of proper care and lack of awareness, this linkage can lead to a serious risk to public health with huge economic penalties [16]. Studying the community socioeconomic status, education and perception of the community on various zoonotic diseases and its risk is a crucial step

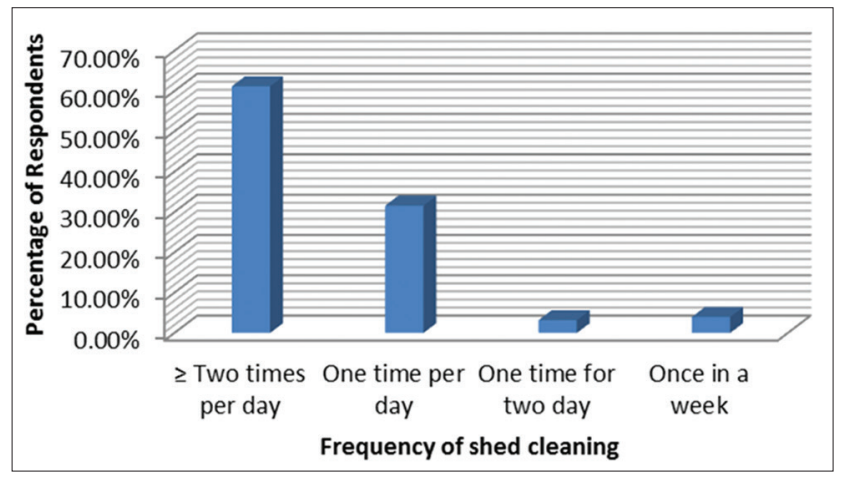

Figure-3: Frequency of shed cleaning.

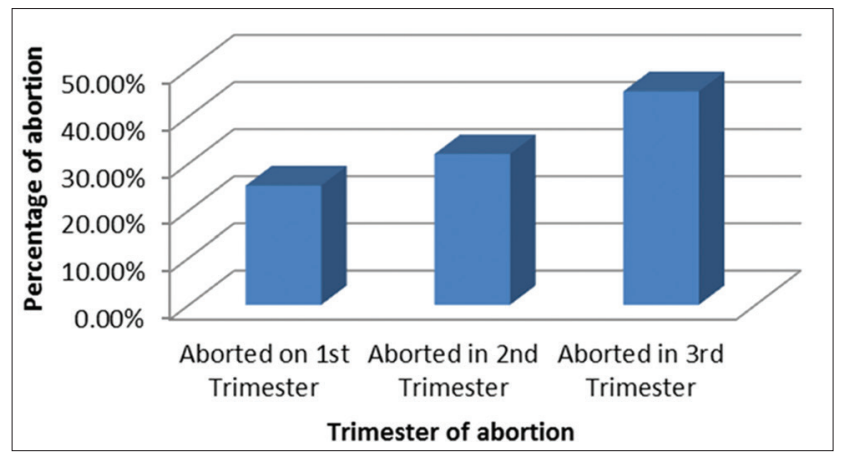

Figure-4: Occurrence of abortion in the Livestock's and the trimester of abortion. 
toward the development and implementation of suitable disease prevention and control strategies.

Table-7: List of zoonotic diseases contracted by the livestock owners in Puducherry region.

\begin{tabular}{lcc}
\hline Parameter & Frequency & Percentage \\
\hline Got disease from animal & 45 & 18 \\
Got respiratory disease & 17 & $37.7(n=45)$ \\
Got digestive disease & 14 & $31.1(n=45)$ \\
Got skin disease & 7 & $15.5(n=45)$ \\
Got other forms of disease & 7 & $15.5(n=45)$ \\
Disease for $<1$ week & 16 & $35.5(n=45)$ \\
Disease for 2-3 weeks & 6 & $13.3(n=45)$ \\
Disease for 1 month & 2 & $4.5(n=45)$ \\
Disease for $>1$ month & 21 & $46.7(n=45)$ \\
\hline
\end{tabular}

Currently, there is no documented evidence available on the awareness of zoonoses among the rural and urban communities in the Puducherry region. Hence, this study was undertaken to assess the awareness on zoonotic diseases among livestock farmers.

Education and socioeconomic status of the livestock farmers

Based on the study conducted in Puducherry, it has been found that majority of farmers involved in livestock rearing are primarily educated (Figure-2). Moreover, the majority of them are able to read and write in their mother tongue.

As for the awareness toward zoonoses is concerned, only $16.4 \%$ of respondents knew that diseases

Table-8: Relationships between different variables analyzed by Chi-square test.

\begin{tabular}{|c|c|c|c|c|c|}
\hline \multirow[t]{3}{*}{ S. No. } & \multirow{3}{*}{$\begin{array}{l}\text { Variable } 1 \\
\text { Income of respondents }\end{array}$} & \multicolumn{3}{|c|}{ Variable 2} & \multirow[t]{3}{*}{ P value } \\
\hline & & \multicolumn{3}{|c|}{ Method of disposal of carcass } & \\
\hline & & Proper disposal & Improper disposal & Total & \\
\hline \multirow[t]{5}{*}{1.} & Income $<10,000$ & 39 & 12 & 51 & 0.1331 \\
\hline & Income $>10,000$ & 127 & 71 & 198 & \\
\hline & Total & 166 & 83 & 249 & \\
\hline & FMD incidence in respondents' cattle & \multicolumn{3}{|c|}{$\begin{array}{l}\text { Occurrence of hand and foot lesions among } \\
\text { respondents }\end{array}$} & \\
\hline & & FMD positive & FMD negative & Total & \\
\hline \multirow[t]{5}{*}{2.} & Hand lesions positive & 17 & 9 & 26 & $0.0208 *$ \\
\hline & Hand lesions negative & 91 & 133 & 224 & \\
\hline & Total & 108 & 142 & 250 & \\
\hline & Frequency of livestock shed cleaning & \multicolumn{3}{|c|}{ Incidence of disease symptoms among respondents } & \\
\hline & Frequency of shed cleaning & Zoonoses positive & Zoonoses negative & Total & \\
\hline \multirow[t]{5}{*}{3.} & $>1$ time per day & 41 & 191 & 232 & 0.5412 \\
\hline & $<3$ times per week & 4 & 14 & 18 & \\
\hline & Total & 45 & 205 & 250 & \\
\hline & Educational level of dog owners & \multicolumn{3}{|c|}{ Deworming their dogs } & \\
\hline & Education level & Dewormed & Not dewormed & Total & \\
\hline \multirow[t]{5}{*}{4.} & HSS graduates & 2 & 2 & 4 & 0.0856 \\
\hline & Primary, SSLC & 2 & 22 & 24 & \\
\hline & Total & 4 & 24 & 28 & \\
\hline & \multirow[t]{2}{*}{ Habit of sleeping inside cattle shed } & \multicolumn{3}{|c|}{ Incidence of disease symptoms among respondents } & \\
\hline & & Zoonoses positive & Zoonoses negative & Total & \\
\hline \multirow[t]{5}{*}{5.} & Sleeping inside cattle shed & 6 & 13 & 19 & 0.1221 \\
\hline & Not sleeping inside cattle shed & 39 & 192 & 231 & \\
\hline & Total & 45 & 205 & 250 & \\
\hline & Educational level of dog owners & \multicolumn{3}{|c|}{ Vaccinating their dogs } & \\
\hline & Education level & Vaccinated & Not vaccinated & Total & \\
\hline \multirow[t]{5}{*}{6.} & HSS, graduate & 3 & 1 & 4 & 0.285 \\
\hline & Primary, SSLC & 9 & 15 & 24 & \\
\hline & Total & 12 & 16 & 28 & \\
\hline & Educational level of respondents & \multicolumn{3}{|c|}{ Treatment of dog bitten animals } & \\
\hline & Education level & Treatment given & $\begin{array}{l}\text { Treatment not } \\
\text { given }\end{array}$ & Total & \\
\hline \multirow[t]{2}{*}{7.} & Primary, SSLC & 217 & 33 & 250 & $<0.0001 * *$ \\
\hline & HSS, graduate & 171 & 79 & 250 & \\
\hline
\end{tabular}

**Significant $(p \leq 0.01), *$ Significant $(p \leq 0.05),{ }^{+}$Significant $(p \leq 0.10)$, ns=Non-significant, FMD=Foot-and-mouth disease 
in animals can be transmitted to humans. About $4.8 \%$, $3.6 \%, 6.8 \%$, and $22.4 \%$ of respondents knew about the zoonotic potential of diseases such as brucellosis, TB, anthrax, and avian flu, respectively. This study indicated a relatively lower level of awareness of the respondents in the study area. Similar lower levels of awareness were also reported by other workers $[17,18]$. This study is in conjunction with the work of others [19] who reported that a high number of farmers had no thorough and accurate knowledge about zoonotic diseases. Some research workers reported [20] higher level of zoonotic awareness of the respondents in Addis Ababa. The difference in the above two study could be due to dissimilarity in the provision of information about these disease and food habits, etc. [18]. Lack of knowledge on zoonotic diseases is due to poor communication between veterinarian and human healthcare professionals [21]. This low level of knowledge and awareness on zoonoses is likely to expose livestock farmers to increased risk of zoonotic diseases.

In this study, regarding the list of zoonotic diseases contracted $(n=45), 37.7 \%$ reported respiratory infection, $31.1 \%$ digestive disturbances, $15.5 \%$ had dermatological problem and $15.5 \%$ reported indiscrete disease such as fever, body pain, headache, and joint pain. The present reports clearly indicate a lack of awareness about the zoonotic diseases.

On the other hand in this study, awareness about rabies was high and $48 \%$ of the respondent had better knowledge about rabies and its management and our analysis showed significance in educational level of respondents and treatment of dog bitten animals. Our present findings are in agreement with another researcher who also has reported the similar findings $[15,22]$.

Like rabies, brucellosis is a very important zoonotic disease and one of the important causative agents of abortion in livestock and is a highly infectious zoonotic disease. In Brucellosis, the classical signs are abortion in the $3^{\text {rd }}$ trimester of gestation and incidence of retained placenta [23]. In this study, about $30 \%$ of the respondents' farm had an incidence of abortion. Among them, 25.3\%, 32\% and $45.3 \%$ of them noted abortions at $1^{\text {st }}, 2^{\text {nd }}$ and $3^{\text {rd }}$ trimester of gestation, respectively. However, only $4.8 \%$ of the respondent knows about brucellosis and only $0.8 \%$ of the respondent knows about vaccination against brucellosis. This may be due to lack of awareness against brucellosis. However, many respondents reported $3^{\text {rd }}$ trimester abortion in their cattle and hence awareness of brucellosis is a need of an hour for control of highly potential zoonotic diseases like brucellosis, knowledge about calf hood vaccination must be initiated to the livestock farmers.

In this study, about $43.2 \%$ of the respondents reported FMD outbreak in their cattle and $24.07 \%$ reported hand and foot lesion after attending the FMD infected animals which was statistically significant. Another worker [24] also reported the similar findings

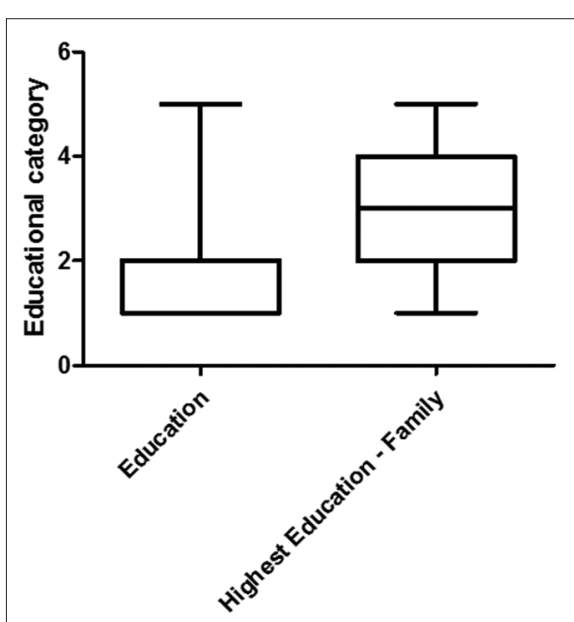

Figure-5: A box and whiskers plot illustrating Education of the respondents to the highest education in the respondents family. The bold line indicates the median. Whiskers represent the $5^{\text {th }}$ and $95^{\text {th }}$ percentiles with lines below and above representing the $0-5^{\text {th }}$ and $95-100^{\text {th }}$ percentiles, respectively. Outliers are indicated by individual points (Category: 1 - Primary education; 2 - SSLC; 3 - Higher secondary; 4 - Undergraduates; 5 - Post-graduates).

that the humans are believed to be slightly susceptible to infection with the FMD virus.

In this study, level of education in the family member was higher when compared to the level of education in the persons who is carrying out farming practices (Figure-5). Hence if the educated family member also involves themselves in the farming practices, implementation of zoonotic awareness and control programs will be effective and easier.

\section{Conclusion}

Lack of awareness about the zoonotic diseases in the present investigation was due to poor communication between veterinarian and human health-care professionals and lack of involvement of educated family members in farming activities. Involvement of educated family members in farming practices can solve this issue. Further creation of zoonotic disease awareness among livestock farmers is of utmost important. Proper disposal of animal waste, good hygienic practices, are extremely important steps in successful control of zoonotic diseases [25].

\section{Authors' Contributions}

KR: Revised the questionnaire for collection of data, framed manuscripts and carried out statistical analysis; AB: Provided valuable suggestions regarding the study design and analysis of the collected data; SD, SHB, RH, MJ and NB: Prepared questionnaire, assisted in framing manuscripts, collected data by personal interview, recorded the data and prepared tables. All authors read and approved the final manuscript.

\section{Acknowledgments}

The authors are highly thankful to Head, Department of Veterinary Public Health and 
Epidemiology, RIVER, Puducherry for providing facilities and allowing us to carry out this work.

\section{Competing Interests} interests.

The authors declare that they have no competing

\section{References}

1. All India Report. (2012) $19^{\text {th }}$ Livestock census, Department of Animal Husbandry, Dairying and Fisheries, Ministry of Agriculture, Government of India, New Delhi, India. p39.

2. World Health Organisation. (2015) Zoonoses. Available from: http://www.who.int/topics/zoonoses/en/. Accessed on 04-05-16.

3. Daszak, P., Cunningham, A.A. and Hyatt, A.D. (2000) Emerging infectious diseases of wild life threat to biodiversity and human health. Science, 287: 443.

4. Woolhouse, M.E.J. and Sequeria, S. (2005) Host range and emerging and re-emerging pathogens. Emerg. Infect. Dis., 11: $1842-1847$.

5. Singh, B.B., Sharma, R., Gill, J.P.S., Aulakh, R.S. and Banga, H.S. (2011) Climate change, zoonoses and India. Rev. Sci. Tech. Off. Int. Epiz., 30: 779-788.

6. WHO. (2002) Future trends in Veterinary Public Health Technical Report Series, 907. Report of a WHO Study Group, Geneva. p1-7.

7. World Health Organisation. (2006) The Control of Neglected Zoonotic Diseases: A Route to Poverty Alleviation. Geneva Report of a Joint WHO/DFID-AHP Meeting with the Participation of FAO and OIE, Geneva, 20-21, September, 2005.

8. Asokan, G.V., Vanitha, A. and Prathap, T. (2011) One health national programme across species on zoonoses: A call to the developing world. Infect. Ecol. Epidemiol., 1: 8293.

9. Wastling, J.M., Akanmori, B.D. and Williams, D.J.L. (1999) Zoonoses in West Africa: Impact and control. Parasitol. Today, 15: 309-311.

10. McDermott, J.J. and Arimi, S.M. (2002) Brucellosis in SubSaharan Africa: Epidemiology, control and impact. Vet. Microbiol., 90: 111-134.

11. Perry, B.D., Randolf, T.F., McDermott, J.J., Sones, K.R. and Thornton, P.K. (2002) In: Investing in Animal Health Research to Allivate Poverty. International Livestock Research Institute (ILRI), Nairobi, Kenya. p133.

12. Jhon, K., Kazwala, R. and Mfinanga, G.S. (2007) Knowledge of causes, Clinical features and diagnosis of common zoonoses among medical practitioners in Tanzania. BMC Infect. Dis., 8: 162. DOI: 10.1186/1471-2334-8-162.

13. Asbjer, E. (2009) Dog Population Management in Malawi and Peru. Project Report, Department of Biomedical Sciences and Veterinary Public Health. Swedish University of Agricultural Sciences. p54. Available from: http://www. stud.epsilon.slu. Se/963/1/asbjer_e_100325.pdf. Accessed on $04-05-16$

14. Swai, E.S., Schoonman, L. and Daborn, C.J. (2010) Knowledge and attitude towards zoonose among animal health workers and livestock keepers in Arusha and Tanga, Tanzania. Tanzan. J. Health Res., 12(4): 282-288.

15. Mosalagae, D., Pfukenyi, D.M. and Matope, G. (2011) Milk producers' awareness of milk-borne zoonoses in selected smallholder and commercial dairy farms of Zimbabwe. Trop. Anim. Health. Prod., 43(3): 733-739.

16. World Health Organization. (2010) Managing zoonotic public health risks at the human -Animal-ecosystem interface. Strong inter-sectoral partnerships in health. Food Saf. Zoonoses. Available from: http://www.who.int/foodsafety. Accessed on 04-05-16.

17. Tebug, S.F., Njunga, G.R., Chagunda, M.G.G., Mapemba, J.P., Awah-Ndukum, J. and Wiedemann, S. (2014) Risk, knowledge and preventive measures of small holder dairy farmers in northern Malawi with regard to zoonotic brucellosis and bovine tuberculosis. Onderstepoort $J$. Vet. Res., 81: 1-6.

18. Babu, A.J., Ramya, P., Rao, L.V., Swetha, C.S., Sudhanthiramani. and Venkateswara R. (2015) A study on the awareness and knowledge of zoonotic diseases among the public in and around Proddatur-YSR Kadapa District, Andhra Pradesh, India. Int. J. Rec. Sci. Res., 67: 5131-5138.

19. Amenu, K., Thys, E., Regassa, A. and Marcotty, T. (2010) Brucellosis and tuberculosis in Arsi- Negele District, Ethiopia: Prevalence in ruminants and people's behaviour towards zoonoses. Tropicultura, 28(4): 205-210.

20. Girma, S., Zewde, G., Tafess, K. and Jilbat, T. (2012) Assessment of awareness on food borne zoonoses and its relation with veterinary public health services in and around Addis Abba. Epidemol. Public Health, 4(2): 48-51.

21. Cripps, P.J. (2000) Veterinary education, zoonoses and public health: A personal prospective. Acta Trop., 76: 77-80.

22. Emmanuel, J., Awosanya, H.O. and Akande, H.O. (2015) Animal health care seeking behavior of pets or livestock owners and knowledge and awareness on zoonoses in a university community. Vet. World, 8(7): 841-847.

23. Ananthnarayan, R. and Paniker, J. (2013) Brucella. In: Arti, K., editor. Textbook of Microbiology. $9^{\text {th }}$ ed. University Press, Hyderabad. p340-343.

24. Radostits, O.M., Gay, C.C.,Hinchcliff,K.W. andConstable,P.D. (2010), Veterinary Medicine, A Textbook of the Diseases of Cattle, Sheep, Goats, Pigs and Horses. $10^{\text {th }}$ ed. Book Power Saunders, London, New York. p1526-1531.

25. Al-Majali, A.M., Talafha, A.Q., Ababneh, M.M. and Ababneh, M.M. (2009) Seroprevalence and risk factors for bovine brucellosis in Jordan. J. Vet. Sci., 10: 61-65. 